\title{
What is temporal ontology?
}

\author{
Natalja Deng
}

(Philosophical Studies; the final publication is available at Springer via

https:/ link.springer.com/article/10.1007\%2Fs11098-017-0893-6)

\begin{abstract}
Temporal ontology is the part of ontology involving the rival positions of presentism, eternalism, and the growing block theory. While this much is clear, it's surprisingly difficult to elucidate the substance of the disagreement between presentists and eternalists (to focus on the most widespread positions). Certain events happened that are not happening now; what is it to disagree about whether these events exist (simpliciter, or else tenselessly)? In spite of widespread suspicion concerning the status and methods of analytic metaphysics, skeptics' doubts about this debate have not generally been heeded, neither by metaphysicians, nor by philosophers of physics. This paper revisits the question in the light of prominent elucidation attempts from both camps (by Ted Sider, Christian Wüthrich, and Tom Stoneham). The upshot is that skeptics were right to be puzzled. The paper then explores a possible re-interpretation of positions in temporal ontology that links it to normative views about how we should live as temporal beings.
\end{abstract}

\section{Introduction}

The aim of this paper is to motivate its title question. It's to get the reader into a mindset where (s)he feels that it's an open question, and one with no obvious answers. 
Though modest, this aim is in the spirit of skeptical views about temporal ontology. Temporal ontology is the part of ontology (the study of what there is) involving the rival views of presentism, eternalism, the shrinking block view, and the growing block view, amongst others. I'll focus mostly on presentism and eternalism.

Presentism in its standard form is roughly the view that only the present or only present things exist(s). (Sometimes 'always' and/or 'necessarily' are added.) Eternalism is usually taken to be the view that all times and/or events exist. Skeptics about temporal ontology deny that the dispute is substantive. The stance taken here is that whether or not the skeptics are right, their doubts have still not been sufficiently heeded. Neither core analytic metaphysics nor philosophy of physics has fully appreciated the extent to which the debate is itself an appropriate object of philosophical puzzlement.

There is also a secondary aim to the paper, which is to explore a take on temporal ontology that links it to normative views about how we should live as temporal beings. This is intended as a possible re-interpretation of the debate, rather than as an interpretation of the debate as it stands (so this suggestion can't dispel the puzzlement the paper tries to induce).

I don't know of a head-on way to induce puzzlement about a debate in someone who feels it's perfectly clear, so my strategy is indirect. I examine prominent attempts at elucidating what's at stake in the debate and show that they are problematic. Failures to illuminate are themselves significant and should go some way towards inducing puzzlement, both about why no illumination has been achieved and, by extension, about the debate itself.

Sections 2, 3, and 4 discuss elucidation attempts by Ted Sider, Christian Wüthrich and Tom Stoneham, respectively. Section 5 concedes that prima facie, elucidation may be had by linking this debate to the one about time's passing, but offers some reasons for caution to 
those attracted to this move. Section 6 explores the link to normative views about how we should live as temporal beings.

As mentioned, I'll take presentism to be the view that only the present, or only present things exist. ${ }^{1}$ As many have pointed out, there are salient readings of this that are trivial. In particular, if 'exists' means exists now, the view says that only present things exist now, which is trivially true. Alternatively, if 'exists' means has existed, exists now, or will exist, then the view is trivially false: dinosaurs have existed but are not present. In interpreting the debate, we want to avoid attributing a trivial view (i.e. a trivially false or trivially true view) to either side. Call this the charity constraint. I'll collectively refer to the various arguments that fit this schema as 'the triviality challenge' (see e.g. Meyer 2005, Dorato 2009, Savitt 2009, Stoneham 2009, Lombard 2010, Balaguer 2014, Tallant 2014).

So 'exists' has to mean something else. The near consensus is that what it means is 'tenseless existence', or else existence simpliciter, i.e. existence full stop.

Some would object to my treating the notions of 'tenseless existence' and 'existence simpliciter' as interchangeable here. For example, Daniel Deasy argues that the triviality challenge is based on the misguided idea that quantifiers are verbs. ${ }^{2} \mathrm{He}$ takes standard presentism to be the thesis that (always) everything is present, and argues that the universal quantifier here isn't a verb and therefore doesn't admit of either a tensed or a tenseless reading.

\footnotetext{
${ }^{1}$ I confine myself to discussing this standard version of presentism, leaving aside Jonathan Tallant's 'existence presentism' (see e.g. Tallant 2014), both because of space limitations and because I think similar problems afflict that version.

${ }^{2}$ (Deasy 2015, 4).
} 
One natural interpretation of Deasy's position is as follows: presentism says that (always) all that exists is present, where 'existence' means existence simpliciter. Fortunately, what follows can be taken as directed either against a formulation based on 'tenseless existence', or one based on 'existence simpliciter'. Nothing hangs on whether both are part of the standard formulation.

Standard presentism, then, is the view that only things that are present exist, full stop. Even when the quantifier's wings are stretched are as wide as they can be, no non-present things (that are still temporal things) are caught by it (I take the metaphor from Mozersky 2011, p. 124). My thesis is that this statement stands in need of elucidation, and that this remains the case even after one has digested prominent attempts at elucidation.

\section{Ideology and ontology}

In 'Writing the book of the world' (2011), Ted Sider uses his influential broader view in meta-metaphysics and related areas to show that the presentism-eternalism debate is substantive. This broader meta-metaphysical view, he says, allows one to make better sense of what is at stake in the debate than do rival meta-metaphysical views. (I won't take a stand on whether that's so.)

To make sense of the dispute, Sider recommends that we think of it as being partly ideological, in the sense that it's partly about which concepts or notions are fundamental or carve nature at its joints: 
'Do tensed concepts [carve at the joints]? [...] [P]hrasing the issue as one about the fundamental "shape" of reality's temporal joints helps to illuminate what are otherwise extremely perplexing questions.' (p. 9)

The support is also intended to go in the other direction: that the broader meta-metaphysical view helps make sense of what's at stake in this and other metaphysical debates adds to the case for it.

The eternalist's ideology is that of first-order predicate logic, including the universal and existential quantifiers. These allow her to describe temporal reality as it fundamentally is, by quantifying over past and future entities and stating what they are like at the times they exist. For example, she can affirm that (fundamentally, speaking strictly, in the ontology room) there exist dinosaurs: $\exists x D x$.

The presentist's ideology is more bloated. It includes not just the notions of first-order predicate logic, but also tense operators. These are one-place sentence operators such as ' $P$ ' (it was the case that...), ' $N$ ' (it is the case that...), ' $F$ ' (it will be the case that...), ' $A$ ' (it is always the case that...), and others. For the presentist, $\phi \leftrightarrow N \Phi$, for all $\Phi$. Thus, $F a$ iff $a$ is now $F$, and $\exists x D x$ iff there now are dinsoaurs. Therefore, the presentist rejects $\exists x D x$, and claims instead that $P \exists x D x$.

According to Sider, the presentist and the eternalist disagree on temporal ideology, i.e. on the shape of nature's temporal joints. They also have a further disagreement about temporal ontology, i.e. on what exists time-wise, or what's in the domain of temporal things. That's because as we've seen, presentists deny, while eternalists affirm, $\exists x D x$, and similarly for lots of other things (not just dinosaurs). 
One skeptical idea Sider considers is that the two sides mean different things by ' $\exists x D x$ '. Presentists think the sentence is true iff there presently exists a dinosaur, whereas eternalists think it's true iff there atemporally exists a dinosaur. Sider maintains that this idea misconstrues what each side intends to mean. Each side intends to mean 'whatever jointcarving meanings are in the vicinity, regardless of whether those meanings satisfy their theories' (p. 277).

He seems to be saying that what the disputants mean by ' $\exists x D x$ ’ isn’t fixed by anything to do with their views. Rather, it's fixed by their intention to mean something joint-carving by all the expressions in ' $\exists x D x$ '. As metaphysicians, they can, if necessary, ensure that all expressions in ' $\exists x D x$ ' carve at the joints, by stipulating that they're to have whatever jointcarving meanings are in the vicinity of the terms in question. As a result, $\exists x D x$ means that there exist dinosaurs, in the sense of existence that is familiar from first-order predicate logic.

One reason one might be puzzled about this is that Sider doesn't think of this sceptic as blaming the quantifier. Yet, the quantifier is one of the few expressions in $\exists x D x$, and one whose meaning it's natural to wonder about here.

So suppose the sceptic is blaming the quantifier. About that, Sider says the participants can stamp their feet, and refer the sceptic back to the case he makes in the rest of the book for the view that quantifiers carve at the joints. The rest of the book offers lots of reasons to include in one's ideology that of first-order predicate logic. And this dispute is to be understood in those terms.

However, this makes things no less perplexing. It's part of the ideological dispute, says Sider, that according to the presentist, nature's temporal joints have a tense operator shape, not 
just a first-order predicate logic shape. Given that ideology, $\exists x D x$ is equivalent to $N \exists x D x-$ it's now the case that there are dinosaurs. At least it's equivalent to this on one of its readings. What is the other reading?

Perhaps this is building too much of the presentist's theory into the meaning of ' $\exists x D x$ '. Then presumably it would also be building too much of the eternalist's theory into the meaning of ' $\exists x D x$ ' to think of it as behaving according to the eternalist's ideology. That is, we also mustn't think of it as attributing existence at some time 'out there' to dinosaurs (whatever that means). It doesn't say that dinosaurs exist atemporally. But then how should we think of the meaning of ' $\exists x D x$ '?

Clearly, much depends on the claim that quantifiers carve at the joints. Sider's main argument for this is an indispensability argument. Physics, like all other domains of enquiry, uses and needs to use quantifiers. Therefore, quantifiers are fundamental, they carve at the joints, much like, as Lewis has shown, certain predicates ('green') but not others ('grue') do.

However, we needn't settle this broader issue. Let's grant for the sake of argument that the world has basic quantificational structure. That is, suppose that there is one notion of existential quantification that is central to all inquiry, and one notion of inquiry such that analytic metaphysics is in principle eligible for inclusion. That still doesn't answer the question as to the meaning of ' $\exists x D x$ ', because the dispute is supposed to concern the nature of time. It's not clear which aspect of the nature of time we thematize when we apply this logical notion to dinosaurs. ${ }^{3}$ What can both sides mean by ' $\exists x D x$ ' that their opposed

\footnotetext{
${ }^{3}$ Lawrence Lombard puts this point beautifully: '[T] here can be a debate between those who think that presently nonexistent things can now be members of classes, and that currently nonexistent things can now be constituents of singular propositions, and that things can have some properties (and bear relations to other things) at times at which they do not exist,
} 
ideologies don't bar them from meaning? Indeed, what is it to have opposing temporal ideologies? What does it mean to disagree about the shape of nature's temporal joints?

Sider also offers the skeptic a relativist way of developing his position. Here's what relativism says. The relativiser finds 'dinosaurs exist' unintelligible, but feels he can make sense of 'dinosaurs exist at time t'. For that reason, he maintains that some fundamental quantifiers have time-slots in them: $\exists_{t}, \forall_{t}$.

Sider raises three objections against relativism, of which I'll comment on the second and third. First, it's is an unattractive ideological view. We already need the non-time-relative quantifier in maths, logic, and physics, so this ideology is 'fractured'. I'll set this aside.

Second, even if relativism is true, and the original ontological dispute made no sense, the original ideological dispute is alive and well. It has merely acquired a new participant. According to the relativiser, the shape of nature's temporal joints is that traced out by temporally relativized quantifiers.

But Sider is wrong to think these three ideological positions are on a par. The relativiser's ideology is importantly different from the other two, because it's intelligible to anyone who understands temporal variation. That is, the relativiser's ideology comes with its own readymade elucidation of what the question about the 'shape of nature's temporal joints' is. It's about what happened when. By contrast, as we've seen, it's not clear how to make sense of the other two ideological positions.

and those who don't think so. But, it seems clear who wins that debate. More importantly, however, it seems clear that such a debate is not about time or the existence of things that exist in time.' $(2010,70)$ 
The third objection Sider raises is that relativism may well pave the way for a new debate about temporal ontology. The relativiser assumes that no one wants to affirm $\exists_{2016} D x$. But why not? Why can't a rogue relativiser affirm this? The dispute would then go as follows. $\exists_{2016} x D x !$ ', says the rogue relativiser. The original relativiser reasons with him. 'No, come on. It's not the case that $\exists_{2016} x D x$. Rather, $\exists_{200 \text { million years } B C} x D x$.' The rogue relativiser replies: 'Hear me out. $\exists_{2016} x D x$. Only $\neg \exists_{2016} x(D x \wedge$ Located - in $-2016(x))$.'

It's hard not to feel that Sider is mis-interpreting the relativiser. In claiming to be able to understand 'dinosaurs exist at t', even as a fundamental claim, the relativiser surely meant to claim no more than that he understands that dinosaurs once walked the earth and then became extinct. His time-relative quantifier, even understood as a joint-carving quantifier, was intended to express no more than that.

So the relativiser should reply to Sider's third objection by pointing out that the envisaged new ontological dispute is no less puzzling than the original dispute. The question is what the rogue relativiser can mean by the time-relative quantifier. It seems clear that the rogue relativiser is expressing the uncontroversial fact about natural history using location-talk: for no time t, existing-t dinosaurs are located in 2016. At any time t, existing-t dinosaurs are only located in (e.g.) the Jurassic era. So what does the time-relative quantifier add? Again, the relativiser intended to capture with the new quantifier no more than the undisputed fact of natural history. He should be as puzzled about his opponent, and the new dispute, as he was about the original one. 


\section{Physics to the rescue?}

Christian Wüthrich has argued extensively that modern physics presents a devastating challenge to presentism. In 'Demarcating presentism' (2011), he responds to skeptical arguments and argues that they fail.

Wüthrich starts out by taking presentism to be the view that the 'the sum total of physical existence can be organized in a three-dimensional manifold'. He maintains that the disagreement is straightforward, since the presentist posits a subset of the events posited by the eternalist:

'[T]here is plenty of room for disagreement, if we accept that there exists a proper subset relation between the set of the [events] of the presentist and the corresponding eternalist set.'

It's true that in some sense, the presentist intends to 'posit' fewer things than the eternalist. For example, Caesars' crossing the rubicon is 'posited' only by the eternalist. However, this is no more than a starting point from which to engage with the triviality challenge. The challenge is to use this kind of preliminary understanding to explicate two opposed, nontrivial theses. It's to explain what it means to disagree about whether a historical event exists. Everyone thinks it existed in the sense that it happened, and no one thinks it exists now in the sense that it's currently happening. Beyond this, what can be at stake? What is it about the nature of events that presentists and eternalists are able to disagree about?

Wüthrich doesn't feel the force of this worry and thinks the following argument by Steven Savitt is based on a simple mistake. Suppose we think of the presentist thesis as

(1) 'Necessarily, if x exists simpliciter, then x presently exists'. 
If we follow Lewis and take 'existence simpliciter' to concern a domain that includes everything in all possible worlds, says Savitt, then (1) equivalent to

(2) Necessarily, if $x$ presently exists or $\mathrm{x}$ did exist or $\mathrm{x}$ will exist or $\mathrm{x}$ possibly exists, then $\mathrm{x}$ presently exists'.

This, Savitt says, is trivially false (see also Meyer 2005). Wüthrich disagrees:

'The problem $[\ldots]$ with Savitt's dismissal of characterizing the debate in terms of existence simpliciter is that it rests on an invalid argument: the presentist interprets existence simpliciter in (1) to have narrow range such as to exclude anything that is non-present, yet (2) will only come out as false if the quantification ranges over at least something that is non-present. But it is of course a necessary condition for an inference to be valid that the range be fixed.'

The idea seems to be that (2) follows from (1) on either a 'presentist' and an 'eternalist' interpretation of the range of quantification, but not if we switch from one to the other. Presentists are committed to (1) only if we keep the range 'tightly presentist', in which case (2) follows but 'becomes non-trivially true' - by the presentist's lights, presumably. Meanwhile, with an 'eternalist' range, (2) follows from (1) too, and both are indeed trivially false, but that's as expected. It's why the eternalist rejects them.

We can agree that talk of (2) doesn't help much in understanding (1), but that, presumably, is Savitt's point. What should either (1) or (2) be taken to say when the range is kept 'tightly presentist'? Indeed, how can that be the right way to put the presentist's position? Presentists say they are not restricting the range of quantification; that's why (1) talks of existence simpliciter. If presentists restrict the domain of quantification when quantifying unrestrictedly, then their position is trivially false. Since all that exists, exists, positing less 
won't do. For reasons of charity, we want to avoid attributing that position to presentists. So what does (1) say? Savitt's point is that (2) doesn't help answer that question.

Wüthrich maintains that our clear understanding of 'physical existence' allows us to answer the question: presentists are saying that only some of all the existing events physically exist. '[W] hat could be more fundamental [...]?' If a contrast class is needed, it is unclear what could keep us, in principle, from starting to list entities which do not physically exist' (2011, $3)$.

But this won't help, for familiar reasons. We're asking what it is for historical events, events that happened, like Caesar's crossing the rubicon, to not physically exist. Such events may in some respects be a little like Santa Claus, or like pseudo-history, but since they did happen, there is an important dissimilarity.

Wüthrich ultimately offers the following solution. Take a four-dimensional manifold $M$ with a certain topological and differential structure. Eternalism, he says, is the view that says all events in $M$ exist and stand in the spatiotemporal relations encoded in the metric $g_{a b}$ defined on $M$. Presentism, on the other hand, partitions $M$ into past, present, and future events. It posits an equivalence relation $S$ whose equivalence classes contain 'simultaneous' events. It then restricts existence to one privileged such class, namely those events 'simultaneous' with the 'here-now'. The first step famously puts it at odds with modern physics, particularly special relativity.

There is a strong temptation to jump from this conflict with physics to the conclusion that the debate must be genuine: if physics rules against a position, it must say something. But what physics straightforwardly conflicts with is the first step, i.e. the idea that simultaneity is absolute or that there is distant simultaneity, and that there is such a thing as a global 'now'. 
Whether it also conflicts with the second step is not so clear. And it's the second step that constitutes presentism.

One way to see this is to consider the position that says the past, present and future all exist. This is a view that has often gone by the name of eternalism. Indeed, this view has gone by the name rather more often than the view Wüthrich calls eternalism. And it too relies on the notion of a global present, since 'past' and 'future' are most likely intended to refer to sets of equivalence classes of $S$. Thus, if we have solved the triviality challenge, the solution has to be contained in the second step, i.e. in the restriction of 'physical existence' to a subset of the events in the manifold. Btu that's just the characterization of the debate we started out with. ${ }^{4}$

Wüthrich is adamant that considerations of the grounding problem (understood as the problem of what makes e.g. 'Caesar crossed the rubicon' true, on presentism) and of temporal passage are out of place in this discussion. He anticipates problems for presentists as to how 'the abstracta relate to the physically existing events', which he sees as related to the grounding problem, but insists that those are not relevant here. Similarly, he says that passage is no necessary part of presentism, and that a 'Heraclitean' demand for a dynamic succession of presents is 'simply misplaced qua objection to the substantiality of the debate'. 'It may well be the case that any attempt to accommodate animation will be frustrated either by triviality or by incoherence', but that's not relevant. Why saddle the presentist with anything so unpleasant? Presentism is an ontological thesis, 'not an ideological statement about the qualities - dynamical or otherwise - of that which exists' (Wüthrich 2013, 2).

In a way the grounding issue is indeed not that relevant. This is because of the charity constraint. We're assuming that presentists can agree that certain events happened, and that

\footnotetext{
${ }^{4}$ Savitt (manuscript, pp. 26-29), which came to my attention after writing this article, argues for a similar conclusion.
} 
propositions expressing this are true. That is, we're assuming that there are ways of solving the grounding problem, if it arises. (The next section discusses an explicit attempt to elucidate the debate through consideration of the grounding problem; I'll argue that it runs into trouble with the charity constraint.)

However, the passage issue is not so easily bracketed. The idea of a view that 'posits' only a subset of some manifold's set of events invites the question of which subset the view 'posits'. 49BC? 1980? A day in 2016? The intended answer is that the answer changes, as time passes. That is, the idea is that it's not a fixed matter which events the view attributes 'physical existence' to. 'The present' is to be understood as an indexical, picking out the time at which it's used. This suggests that temporal passage and the 'Heraclitean' idea of a dynamic succession of presents are not optional add-ons to a 'core' presentist thesis but rather part and parcel of the view. I'll come back to this point in section 5 below. For now what matters is that Wüthrich's subset proposal is of no help with the triviality challenge. Keeping the question of whether what exists changes firmly separate from a supposed 'core' presentist thesis only makes the position more puzzling.

It's easy to mis-construe the dialectical significance of the triviality challenge. Wüthrich, following others, treats it as a problem for presentists only. But that can't be right. ${ }^{5}$ A challenge to a debate can't leave one side ‘the uncontested game in town' (Wüthrich 2011, 5). For one side to win, the other has to lose, and both have to be well 'demarcated'.

\footnotetext{
${ }^{5}$ Takeshi Sakon also makes this point (2015: 1091).
} 


\section{Grounding the debate}

Tom Stoneham shares these worries about the notion of event's existence simpliciter, or tenseless existence. But he thinks the debate can still be made intelligible if we think of it in terms of truthmaking, and thus in relation to a version of the grounding problem. ${ }^{6}$

According to Stoneham, both the eternalist and the presentist accept a version of the following truthmaker principle, TM (also known as truthmaker maximalism):

'(TM) [For all propositions $<\mathrm{p}>$ :] If $<\mathrm{p}>$ is true, then there exists some object $\mathrm{x}$, such that the existence of $\mathrm{x}$ strictly implies the truth of $<\mathrm{p}>$.' (212)

The presentist accepts the following disambiguation of TM:

'(TM1) [For all propositions $<\mathrm{p}>$ :] If $<\mathrm{p}>$ is true, then there now exists some object $\mathrm{x}$, such that $<\mathrm{x}$ exists $>$ strictly implies $<\mathrm{p}>$ '? $(212)$

The eternalist rejects this but upholds a different disambiguation of TM:

'(TM4) [For all propositions $<\mathrm{p}>$ :] If $<\mathrm{p}>$ is true, then either there is, was or will be some object $\mathrm{x}$, such that $<\mathrm{x}$ exists $>$ strictly implies $<\mathrm{p}>$.' (213)

This, Stoneham says, is a genuine disagreement, because TM1 is non-trivial.

The first thing to note about this proposal is that TM4 is itself puzzling. We are to make do without any notion of existence that isn't the familiar tensed notion. So $<x$ exists $>$ here is presumably present-tensed. But why would a dinosaur $\mathrm{x}$ that used to exist be such that $<\mathrm{x}$

\footnotetext{
${ }^{6}$ Jonathan Tallant also rejects Stoneham's proposal, but his criticisms are based on
} substantial intuitions about which truthmaker principles to endorse in general (Tallant 2014). 
now exists $>$ strictly implies < dinosaurs existed $>$ ? And even if it was, why would that matter, since $<\mathrm{x}$ now exists $>$ is presumably false?

So what, one might say. The eternalist still rejects TM1, so there is still a substantive disagreement. But Stoneham is right to frame the discussion in terms of TM, and to emphasize that both sides must accept a version of TM. Mere rejection versus acceptance of TM1 signals a disagreement alright, but not one whose substance is clear. If the eternalist rejects TM1, we naturally want to know whether that is because he rejects TM (in toto), or because he has a different view of what makes true certain propositions. If he rejects TM, we want to know why, and how the resulting view relates to a view that includes TM1. If he accepts TM, we need to know in which form he accepts it, if not in the form of TM4.

Note that the difficulty arises precisely from wanting to do without the notion of tenseless existence. The following disambiguation also does without that notion, and is free of these problems. However, as Stoneham notes, it's trivially true:

'TM2: [For all propositions $<\mathrm{p}>$ :] If $<\mathrm{p}>$ is true, then either there exists some object $\mathrm{x}$, such that $<\mathrm{x}$ exists $>$ strictly implies $<\mathrm{p}>$, or there existed some object $\mathrm{x}$ such that $<\mathrm{x}$ existed $>$ strictly implies $<\mathrm{p}>$, or there will exist some object $\mathrm{x}$ such that $<\mathrm{x}$ will exist $>$ strictly implies $<\mathrm{p}>$ '(212)

To understand the disagreement over TM1, we need to know what it's opposed to, while not hearing it as trivially false.

However, suppose for the sake of argument that TM4 is not puzzling at all. It seems the presentist can accept it too. TM4, after all, is weaker than TM1. It just (somehow) says all truthmakers are such that they either existed, exist, or will exist. TM1 goes further and says that in particular, they all exist now. 
There is of course no formal problem with this, but on closer inspection it too is puzzling. TM4 is the defining principle of eternalism, and yet the presentist accepts it too. For the presentist, as for anyone else, < dinosaurs existed $>$ is true (or so we're charitably assuming). So dinosaurs existed. And that's all it takes to for them to make true 'dinosaurs existed', according to TM4. Why then posit TM1 in addition - how can 'dinosaurs existed' not already have a truthmaker, even on presentism?

The solution to all these worries is to re-introduce tenseless existence, or existence simpliciter. For the presentist, dinosaurs may have existed, but they don't exist, and that's what makes them unfit for truthmaking. Only existing things can do that, and they only include presently existing things, like presently existing uninstantiated dinosaur haecceities. By contrast, for the eternalist, dinosaurs exist, so they can do the job. But of course this is to give up the game in the context of Stoneham's discussion. Talk of truthmaking, contra Stoneham, doesn't allow one to side-step intelligibility problems afflicting notions like tenseless existence.

\section{A concession}

In section 3 I suggested that temporal passage is part and parcel of the view that presentism is supposed to be. But if that's so, then doesn't the passage issue offer a way to elucidate what's at stake?

The short answer is that for all that I'll say in this paper, it does. The link to temporal passage offers a prima facie promising way to make sense of what's at stake. The dynamicitystasis contrast exerts a powerful pull on the philosophical imagination. There are reasons to 
think the contrast is less substantial than it seems, but I won't argue for that here. ${ }^{7}$ The claim in this paper is that it's difficult to make sense of temporal ontology as long as one brackets the passage issue. Since, as we have seen, the link between presentism and temporal passage is contested, this is in a way a small concession. ${ }^{8}$

Nonetheless, it's worth saying a little more about the connection. The reason passage is relevant is that it can feel illuminating to be told that on presentism (as on other noneternalist views e.g. the growing block view), what's in one's 'temporal ontology' changes. This claim can seem to give one an inkling of what it is to include an event in one's 'temporal ontology' in the first place.

However, one caveat can be noted right away. A large part of what makes the dynamicitystasis contrast compelling is that it's bound up with our sense of freedom and of the openness of the future. That's especially so in the context of the temporal ontology debates. It can seem as if there must be something at stake, since one position intuitively threatens our freedom and the others don't. And as will become clear shortly, I want to concede that it may be possible to affix meaning to positions in temporal ontology via our sense of their practical import (more on this below). But the idea that eternalism threatens our freedom is problematic. Therefore, any support it lends to the sense of a dynamicity-contrast between presentism and eternalism is compromised.

Stoneham's discussion demonstrates the problem. He helpfully distinguishes between determinism, bivalence, and eternalism. Determinism is the thesis that facts about the present plus the laws of nature entail the facts about the future (as well as, we may add, the

\footnotetext{
${ }^{7}$ See e.g. Deng 2013.

${ }^{8}$ See also the closely related debate over whether presentism is a version of the A-theory (e.g. Tallant 2012).
} 
past). By 'bivalence' he means bivalence for future contingents, i.e. the view that future contingent propositions are true or false. The upshot of his discussion is that whether the future is open depends on whether eternalism is true, i.e. whether the truthmakers stay the same over time. And this issue is orthogonal to whether determinism holds.

Both eternalism and determinism imply bivalence, but for different reasons. On eternalism, the current facts include those about the future, whereas on determinism, the current facts (perhaps in addition, on eternalist determinism) entail those about the future.

The point I want to make about this is that the (prima facie!) threat to freedom posed by determinism is rather more straightforward than any supposed threat posed by eternalism. (So I might also have said that if there's an issue about openness, understood as one about our freedom, it's to do with determinism; but we needn't quibble about the label 'openness'.) The determinism thesis is relatively clear: given the laws, the present (or any other) state of the world fixes its state at all times. But on reflection, it's still not clear what it means to say that the present state includes the future state, or that the facts that presently obtain include future facts (i.e. facts about the future). And that's highlighted by Stoneham's point that eternalism is compatible with a lack of determinism. On a non-determinist eternalism, the present state and the laws leave open what will happen. But future facts form part of the truthmaker base. Should that worry one? It's simply not clear. The conviction that eternalism threatens our freedom is predicated on a firmer grasp on eternalism than anyone should profess to have. 


\section{On living in the present}

Let's now revisit the idea that it may be possible to affix meaning to positions in temporal ontology via our sense of their practical import. Admittedly, this way of putting it can't be quite right. What does 'their' refer to - if the positions have practical import, how can they lack substance? So here's a better way of putting it. It may be possible to affix meaning to positions in temporal ontology via certain practical, and in particular normative, aspects of our lives as temporal beings. The meaning in question can't be the meaning the positions currently have (if any); so this doesn't answer the difficulty the paper has grappled with. Rather, this final section explores a possible re-interpretation of temporal ontology.

To begin with, note that the charity constraint has played an important role in the previous sections. The constraint was that neither side should end up trivial. For example, neither side should end up classifying the ordinary claim 'dinosaurs existed' as false, because that, arguably, makes that side's view trivially false. Or take the really radical view on which all ordinary past and future tensed claims are false. (I am ignoring the notion of 'quasi-truth' here.) On such a view, one might say, there was no past, and there will be no future. The charity constraint rules such interpretations out. Perhaps it isn't always appropriate to apply it. Perhaps there have been some who have defended such radical views under the label 'presentism'. But by and large, the position labelled 'presentism' is intended to be much less radical than that. ${ }^{9}$ By and large, the charity constraint is in place for good reason.

\footnotetext{
${ }^{9}$ Pace Lewis: 'In saying that there are no other times, as opposed to false representations thereof, [presentism] goes against what we all believe. No man, unless it be at the moment of his execution, believes that he has no future; still less does anyone believe that he has no past.' $(1986,204)$
} 
However, there is a view that only the present 'exists' that is radical in a different way. So far, there has been a presupposition that the debate comfortably fits into theoretical philosophy and, in particular, into metaphysics understood as a subject that aims to describe the world, in much the same way as science (construed in a realist way) does. If we now ask again what it could mean to say of a past event that it doesn't exist, one possible answer lifts that presupposition. To say a past event doesn't exist (simpliciter) is to deny that it should play any role in a person's emotional and mental life, or perhaps to deny that it should play the role past events usually play in people's emotional and mental lives. It's to take the existence simpliciter of an event to be the feature that makes an event worthy of a (certain kind of) practical response. ${ }^{10}$ Put simply, it's to take 'only the present exists' to be synonymous with the advice to 'live in the present'.

One way to develop this latter idea is suggested by Kieran Setiya's philosophical diagnosis of the midlife crisis as a symptom of a life dominated by 'telic' activities rather than 'atelic' ones (Setiya 2014). Telic activities are oriented towards a final state: buying a house, starting a family, getting a job, walking to the shops. Atelic activities, on the other hand, are activities that aren't so oriented, and which can't be completed (though one can of course cease engaging in them): spending time with one's family, doing one's job well, living a decent life, going for a walk. The idea is that atelic activities help us relate to time in the way most conducive to avoiding a particular emotional predicament. As Setiya notes, this is a philosophical take on the familiar advice to 'live in the present'. The claim of this section is that one can reinterpret the ontological slogan 'only the present exists' by equating it with the recommendation to relate to time in this way. On this view, presentism doesn't aim to describe time; rather, it aims to guide our relationship to it.

\footnotetext{
${ }^{10}$ Cf Cockburn 1997.
} 
So far this has been about presentism only, but there are also normative developments of eternalism. Perhaps Spinoza is relevant here; think of the injunction to have similar attitudes towards an event no matter whether it's past, present or future. Such an eternalism would also amount to an injunction to treat the past and the future differently from how we usually treat them, but the recommended attitude(s) would be different.

The growing block view would perhaps most naturally be re-interpreted as an endorsement of attitudes as they usually are. Past and future events play very different roles in our emotional and mental lives. The view that the past and the present exist but the future does not might amount to an endorsement of this emotional asymmetry.

Thus, on this way of thinking, both presentism and eternalism would amount to revisionary views, involving recommendations to change aspects of how we live our lives as temporal beings. In particular, both would recommend jettisoning the emotional asymmetry.

A natural response to this kind of approach is that it betrays confusion. There is the question of the existence of events. And perhaps there is also a question about the intrinsic value that attaches to certain events. And we can ask how these two questions relate to one another, and whether either notion can play a justificatory role for emotions and other attitudes. But at least some of these connections will be hard to argue for. Why should the existence of events imply anything about their intrinsic value, much less anything directly about the justification of attitudes? It certainly doesn't do much to explain our attitudes (Callender 2012); so why should it justify?

I feel the force of this worry. But I'm not sure it's the only way of looking at the matter. The claim isn't that there is a close connection between positions in temporal ontology and claims about the intrinsic value of past and future events, or between positions in temporal 
ontology and claims about the justification of emotions and other attitudes. Rather, the claim is that there is a way of re-interpreting the positions on which the link to normativity is constitutive of their content.

Some motivation for looking at things this way derives from the main claim of the paper. There is a real difficulty with making sense of the notion of an event's existence simpliciter. At the same time, there is an unabating and thoroughly familiar tradition of making such claims outside of the ontology room. That tradition, it seems, constitutively links the (non)existence of events with the justification of attitudes. Why not think this is a way to construe the notion?

Here's a reason why not: it's not clear why this should count as a re-interpretation. Doesn't my suggestion just amount to affixing a bizarre new meaning to familiar strings of words, entirely unrelated to their actual, current meaning?

But this objection can be met. First of all, it's hard to say what counts as a re-interpretation since the current meaning of these positions is unclear. Second, and more importantly, keep in mind that the puzzlement emphasized throughout concerned not existence simpliciter per se, but the notion of an event's or time's existence simpliciter, when that's understood as a theoretical notion. By contrast, it doesn't seem bizarre to couch practical injunctions about how to relate to time in terms of events' or times' (non)existence simpliciter. There, the notion of an event's existence makes some sense. Moreover, this is the same notion of existence as the one intended to play a role in temporal ontology, the logical notion familiar from first-order predicate logic. So there seems to be enough continuity here to speak of a re-interpretation. 
This has been no more than a brief exploration of the viability of this kind of approach to temporal ontology. In a longer treatment, more would have to be said about the attitudes in question, and about potential wider implications for how to understand ontological claims.

In closing, it's worth pointing out that such a re-interpretation would not threaten claims about the descriptive nature of other debates in the philosophy of time. Arguably, as long as physics itself gives us no reason to make use of ontological distinctions in connection with time, the fate of temporal ontology need not concern us (qua theoretical philosophers). In particular, there could still be many other substantive, descriptive disagreements in the philosophy of time. Their substantivity would be a consequence of their close link to controversies regarding the nature of time and spacetime in physics.

\section{Conclusion}

I have examined three prominent attempts at elucidating what's at stake between presentists and eternalists. None of them should leave us satisfied: as regards Sider's position, we should be puzzled about what it is to disagree about the shape of nature's temporal joints; as regards Wüthrich's position, we should keep firmly in mind that an answer to the skeptic would require two opposed non-trivial theses; and as regards Stoneham's proposal, talk of grounding only helps if we can also help ourselves to the notion of existence simpliciter as applied to events, in which case there is no need for talk of grounding (in order to elucidate what's at stake). I then conceded that for all I've said here, a link to the passage debates may provide elucidation, but also suggested that there is reason to be cautious about this link. The sense that there is a dynamicity-stasis contrast between positions in temporal ontology partly derives from the idea that eternalism somehow threatens our freedom. And that idea 
is problematic, because it too presupposes a firmer grasp on eternalism than anyone should profess to have.

Finally, I briefly sketched a possible take on positions in temporal ontology on which they amount to recommendations to relate to time in particular ways. On this re-interpretation (which is not intended as an account of what's currently at stake, if anything), presentism would amount to the recommendation to 'live in the present', which has recently been given a philosophical spin by Kieran Setiya. Eternalism might, in a Spinozistic vein, amount to the recommendation to have similar attitudes to events no matter when they happened. In closing, I pointed out that such a re-interpretation need not threaten claims about the descriptive nature of non-ontological debates in the philosophy of time. ${ }^{11}$

\section{References}

Balaguer, M. (2014), 'Anti-metaphysicalism, necessity, and temporal ontology', Philosophy and phenomenological research, 89 (1), pp. 145-167.

Callender, C. (2012), 'Time's ontic voltage', in Bardon, A. (ed.), The Future of the Philosophy of Time, Routledge Studies in Metaphysics; see also Callender, C. (forthcoming) What makes time special, Oxford: Oxford University Press.

Cockburn, D. (1997), Other Times: Philosophical Perspective on Past, Present and Future, Cambridge University Press.

Deasy, D. (2015), 'What is presentism?’, Nous 50 (4), pp. 1-20.

${ }^{11}$ Thanks to Jonathan Tallant, Giuliano Torrengo, David Ingram, Steven Savitt, Geurt Sengers, and audience members in Milan, Cambridge and Rotterdam for helpful comments on various drafts. This paper was written while I was a member of the TWCF project 'Theology, philosophy of religion, and the sciences'. 
Deng, N. (2013), 'Fine’s McTaggart, temporal passage, and the A versus B debate', Ratio 26 (1), pp. 19-34.

Dorato, M. (2009), 'The irrelevance of the presentist/eternalist debate for the ontology of Minkowski spacetime', in Dieks, D. (ed.), The Ontology of Spacetime, Vol. 1, Philosophy and foundations of physics, Elsevier.

Lewis, D. (1986), On the Plurality of Worlds, Oxford: Blackwell Publishers.

Lombard, L. (2010), 'Time for a change: a polemic against the presentism/eternalism debate', in Campbell, J., O’Rourke, M., Silverstein, H. (eds.), Time and Identity, MIT Press.

Meyer, U. (2005), 'The presentist's dilemma', Philosophical studies 122 (3), pp. 213-225.

Mozersky, J. (2011), 'Presentism', in Callender, C. (ed.), The Oxford Handbook of Philosophy of Time, Oxford: Oxford University Press.

Sakon, T. (2015), 'Presentism and the triviality objection', Philosophia 43 (4), pp. 1089-1109.

Savitt, S. (2009), 'Presentism and eternalism in perspective', in Dieks, D. (ed.), The Ontology of Spacetime, Vol. 1, Philosophy and foundations of physics, Elsevier.

Savitt, S. (manuscript, 2011), 'Chronogeometrical determinism and the local present', http://philsci-archive.pitt.edu/8481/.

Setiya, K. (2014), 'The midlife crisis', Philosophers' imprint, 14 (31).

Sider, T. (2011) Writing the book of the world, Oxford: Oxford University Press.

Stoneham, T. (2009), 'Time and truth: the presentism-eternalism debate', Philosophy 84 (2), pp. 201-218. 
Tallant, J. (2012), '(Existence) presentism and the A-theory’, Analysis 72 (4), pp. 673-681.

Tallant, J. (2014), 'Defining existence presentism', Erkenntnis 79 (3), pp. 479-501.

Wüthrich, C. (2011) 'Demarcating presentism', in Henk de Regt, Samir Okasha \& Stephan Hartmann (eds.), EPSA Philosophy of Science: Amsterdam 2009. Springer 441--450.

Wüthrich, C. (2013) 'The fate of presentism in modern physics', in Ciuni, R. \& Miller, K. (eds.), New Papers on the Present, Philosophia. 